\title{
Prolonged survival of islet allografts in mice treated with rosmarinic acid and anti-CD154 antibody
}

\author{
Da-Yeon Jung ${ }^{1}$, Eun-Young Kim ${ }^{1}$, \\ Sung-Yeon Joo', Jae Berm Park ${ }^{2}$, Cheol Moon', \\ Sa Hyun Kim ${ }^{1}$, Eun-Young $\mathrm{Sim}^{1}$, Jae-Won Joh ${ }^{2}$, \\ Choon Hyuck Kwon ${ }^{2}$, Ghee-Young Kwon ${ }^{3}$ and \\ Sung-Joo Kim ${ }^{1,2,4}$ \\ ${ }^{1}$ Transplantation Research Center \\ Samsung Biomedical Research Institute \\ ${ }^{2}$ Department of Surgery \\ ${ }^{3}$ Department of Pathology \\ Samsung Medical Center \\ Sungkyunkwan University School of Medicine \\ Seoul 135-710, Korea \\ ${ }^{4}$ Corresponding author: Tel, 82-2-3410-3476; \\ Fax, 82-2-3410-0040; E-mail, kmhyj111 @ hotmail.com
}

\section{Accepted 19 November 2007}

Abbreviations: IEQ, islet equivalents tolerance; IPGTT, intraperitoneal glucose tolerance test; Ros A, rosmarinic acid

\begin{abstract}
Pancreatic islet transplantation can correct the abnormal glucose metabolism of Type 1 diabetes. Although immunosuppressants greatly reduce the acute rejection rate in transplant patients, the long-term side effects can be debilitating. Therefore, researchers are seeking to develop new immunosuppressive regimens that induce maximal levels of immunosuppression with minor side effects. Rosmarinic acid (Ros A) is a secondary metabolite of certain herbs and has multiple biological activities, including anti-inflammatory effects. Here, we have investigated whether treatment of mice with a combination of Ros A and anti-CD154 monoclonal antibody (MR1) improves islet allograft survival in a murine model. After transplantation, the mice were treated with either Ros A, MR1, or both (the "double" treatment). Allograft survival was prolonged in the double-treated animals compared to animals that received only Ros A or MR1. As is the case with the single-treated animals at 15 days after transplantation, the double-treated recipients did not display a significant decrease in the expression of cytokines or the population of activated T cells. Infiltrating $\mathrm{CD}^{+} \mathrm{T}$ cells were reduced in the MR1- or double therapy relative to control or RosA group. However, at the same time
\end{abstract}

point, double-treated graft showed fewer apoptotic cells and increased expression of insulin and glucagons, compared to the single-treatment groups. Furthermore, long-term ( $>150$ days) allografts that were received with double therapy exhibited larger islet clusters and contained more insulin- and glucagon-positive cells, relative to the MR1-treated grafts. In conclusion, treatment with both Ros A and MR1 has a synergistic effect in murine islet allotransplantation.

Keywords: apoptosis; CD40 ligand; graft survival; immunosuppressive agents; islets of Langerhans transplantation; rosmarinic acid

\section{Introduction}

Type 1 diabetes is a chronic inflammatory autoimmune disease characterized by the impaired function and death of pancreatic islet $\beta$-cells. Pancreatic islet transplantation is currently under active clinical evaluation as a new therapeutic modality for patients with Type 1 diabetes (Porte, 1991; Tisch and McDevitt, 1996; Ricordi, 2003). Immunosuppressive drug regimens have been shown to inhibit rejection of islet grafts while maintaining the graft's ability to secrete insulin, thus freeing islet graft recipients from the burden of daily insulin injections. Although these immunosuppressants greatly reduce the acute rejection rate in transplant patients, the long-term side effects can be debilitating. Therefore, scientists are engaged in the development of new immunosuppressive regimens that induce maximum immunosuppression while keeping side effects at a minimum. Numerous approaches for achieving the prolonged survival of islet grafts have involved the use of T cell-targeted mAbs or drugs (Eng et al., 1991; Hojo et al., 1999; Jung et al., 2006).

In the context of organ transplantation, stimulated $T$ cells can attack the graft, leading to its impaired function and death. After antigen recognition by a T cell, tumor necrosis factor CD154 binds to CD40 and thus participates in T cell costimulation (Molano et al., 2001). Treatment of graft recipients with a mAb to CD154 (MR1) induces long-term survival of islet allografts in rodent models (Parker et al., 1995; Zheng et al., 1999) and nonhuman primates (Kenyon et al., 1999). Also, a remarkable level of allograft and xenograft 
survival has been achieved by the treatment of graft recipients with MR1 plus CTLA-4lg, which also blocks T-cell co-stimulation (Lenschow et al., 1992; Molano et al., 2001). Furthermore, in murine islet allograft and xenograft transplantation recipients, we have also observed beneficial effects when the mice are treated simultaneously with the immunosuppressive drug deoxyspergualin (DSG) and monoclonal antibodies to CD45RB and CD154 (Jung et al., 2006).

Rosmarinic acid (Ros $A$, also known as $\alpha$-ocaffeoyl-3,4-dihydrocyphenyl-lactic acid) is a phenolic compound found in large amounts in a variety of Labiatae herbs (al-Sereiti et al., 1999) and has diverse immunoregulatory functions, including antimicrobial, antioxidant, anticyclooxygenase, and anticomplement activities (van Kessel et al., 1986; al-Sereiti et al., 1999; Kelm et al., 2000). A recent study reported that Ros $A$ inhibits $T$ cell receptor (TCR)-induced $\mathrm{Ca}^{2+}$ influx, IL-2 expression, and subsequent T cell proliferation (Won et al., 2003). Also, Ros A induces Lck- dependent apoptosis in T and NK cells, but not in Lck-deficient B cells and monocytes (the Lck protein is a Src-family tyrosine kinase involved in $\mathrm{T}$ cell signal transduction) (Hur et al., 2004). Moreover, a combined therapy of Ros A and rapamycin (Rapa)-two differently functioning immunosuppressants-synergistically inhibits T-cell proliferation and consequently prolongs graft survival (Yun et al., 2003). In addition, Osakabe et al. (2002) observed that Ros A inhibits inflammation in animal models of liver injury via downregulation of reactive oxygen species (ROS). Although these various functions of Ros $A$ have been reported, very little is known regarding the mechanism of action of Ros $A$ in the pancreatic islet transplantation model. In the present study, we deciphered the effects of Ros A and MR1 combined therapy on the survival and function of islet allografts in mice with Type 1 diabetes.

\section{Materials and Methods}

\section{Animals and induction of diabetes}

Adult male 12-week-old BALB/c $\left(\mathrm{H}-2^{\mathrm{d}}\right)$ mice (Jackson Laboratories, Bar Harbor, ME) served as allogeneic islet donors. Male inbred C57BL/6 (B6, $\mathrm{H}-2^{\mathrm{b}}$ ) mice weighing between 25 and $30 \mathrm{~g}$ were used as recipients of islet grafts. All animals were housed under specific pathogen-free conditions and in accordance with the Samsung Biomedical Research Institute's Principles of Laboratory Animal Care and Guide for the Use of Laboratory Animals. To induce diabetes, 12-week-old C57BL/6 mice were given serial I.P. injections of streptozo- tocin (STZ) (180 mg/kg per mouse per day) (Sigma-Aldrich, St. Louis, MO). Blood glucose concentrations were measured in whole-blood samples collected from the tail veins of the injected mice with the use of Accu-Chek Advantage Glucose Monitors (Roche Diagnostics, Indianapolis, IN). Diabetic mice that had non-fasting blood glucose values of $>300 \mathrm{mg} / \mathrm{dL}$ for more than 2 consecutive days were used as recipients of islet grafts.

\section{Islet isolation and transplantation}

Islets were isolated from BALB/C mice by collagnenase $P$ digestion $(0.8 \mathrm{mg} / \mathrm{ml}$; Roche Diagnostics) followed by purification in Ficoll gradients (Sigma-Aldrich) (Gotoh et al., 1985). After purification, the islets were cultured overnight at $37^{\circ} \mathrm{C}$, $5 \% \mathrm{CO}_{2}$ in M199 medium (Gibco, Long Island, NY) supplemented with 10\% FBS (Hyclone, Logan, UT), $2 \mathrm{mM}$ L-glutamine, $100 \mathrm{U} / \mathrm{ml}$ penicillin, and $100 \mu \mathrm{g} / \mathrm{ml}$ streptomycin. Approximately 300 IEQ (Islet Equivalents) of BALB/c mouse islet cells, which constitutes a marginal islet mass (Kaufman et al., 1994), were transplanted under the left renal capsule of diabetic C57BL/6 recipient mice. Blood glucose concentrations in the recipient mice were monitored biweekly after transplantation. Non-fasting blood glucose concentrations that were $>200$ $\mathrm{mg} / \mathrm{dL}$ for 2 consecutive measurements in a single week were considered to be evidence of loss of graft function.

\section{Anti-rejection therapies}

The allograft recipients were treated with $250 \mu \mathrm{g}$ of hamster anti-mouse CD154 mAb (MR1) administered by I.P. injection on $0,2,4,6$, and 8 days after islet transplantation. Some mice were also treated with $200 \mathrm{mg} / \mathrm{kg}$ of Ros A administered by I.P. injection daily for 8 consecutive days after islet transplantation. Recipient mice were subsequently divided into four separate treatment groups, which received either saline (control, group 1), Ros $A$ alone (group 2), MR1 alone (group 3), or Ros A plus MR1 (the "double" group).

\section{Intraperitoneal glucose tolerance test (IPGTT)}

The intraperitoneal glucose tolerance test (IPGTT) was performed on graft recipients from all four treatment groups at $15,85,123$, and 153 days after transplantation. Briefly, after overnight fasting, unanesthetized mice were injected IP with a 50\% glucose solution ( $2 \mathrm{~g} / \mathrm{kg}$ body $\mathrm{wt}$ ). Plasma glucose concentrations were then measured at $0,15,30$, 
$45,60,90$, and 120 min after glucose injection.

\section{Cytokine detection}

Splenocytes from the C56BL/6 transplant recipients $\left(2 \times 10^{6}\right.$ cells $)$ were harvested 15 days after transplantation and cultured in the presence of anti-CD3 mAb $(5 \mu \mathrm{g} / \mathrm{ml})$ plus anti-CD28 mAb (2 $\mu \mathrm{g} / \mathrm{ml}$ ) for $72 \mathrm{~h}$ at $37^{\circ} \mathrm{C}, 5 \% \mathrm{CO}_{2}$. Splenocyte supernatants were collected and subjected to ELISA for IL-4 and IFN- $\gamma$ (R\&D Systems, Minneapolis, $\mathrm{MN})$.

\section{Antibodies and flow cytometry analysis}

Flow cytometry was used to determine the amount of lymphocyte engraftment in splenocytes from the C57BL/6 islet recipients, which were also adoptive recipients of spleen cells from the donors. Phenotypic analysis of isolated splenocytes was performed 15 days after transplantation. To measure the various T cell subtypes, we used FITC- or phycoerythrin (PE) -conjugated anti-mouse CD3, CD4, CD8, CD25, and CD69 antibodies (BD PharMingen, San Diego, CA). $\mathrm{CD}^{+}, \mathrm{CD}^{+}$, and $\mathrm{CD} 69^{+}$ $T$ cell populations were separated and analyzed for the presence of $\mathrm{CD}^{+} \mathrm{T}$ cells and $\mathrm{CD} 25^{+}$cells. Negative control experiments used mouse or rat IgG fluorochrome conjugates of the appropriate isotype. Analysis of the samples was performed on a FACSCalibur flow cytometer (Becton Dickinson, Braintree, MA), acquiring at least 10,000 events per sample. Data were analyzed using Cellquest software (Becton Dickinson).

\section{Histological analysis}

In order to assess short-term graft function, the graft-bearing kidneys were removed from the recipients 15 days after transplantation. For the analysis of long-term graft function, kidneys were removed from recipient mice 164 days after transplantation. Hyperglycemic long-term surviving recipients, whose grafts had apparently been rejected, were sacrificed immediately. Only normoglycemic mice were nephrectomized, and their grafts were allowed to survive in culture in order to examine islet function. The graft-bearing kidneys were fixed in $10 \%$ formalin and prepared for histological analysis. Paraffin-embedded tissue was sectioned at 4- $\mu \mathrm{m}$ intervals and either stained with hematoxylin-eosin or processed for immunoperoxidase histochemistry with antibodies specific for CD3 (clone MCA1477; Serotec, Oxford, UK), insulin (Dako, Carpinteria, CA), and glucagons (Dako). Apoptotic cells were visualized using the
TUNEL kit (Calbiochem, San Diego, CA) according to the manufacturer's instructions. The results were scored semiquantitatively by averaging the number of TUNEL ${ }^{+}$cells/area at a magnification of $\times 40$. A qualified pathologist who was unaware of the treatment status of the transplanted graft donors evaluated all islet graft specimens for the presence of inflammatory cells, insulin, glucagons, and apoptotic cells. Controls included the omission of primary antibodies and the use of speciesmatched nonbinding control antibodies.

\section{Data analyses}

All reported values were expressed as the mean \pm SD. Statistical analysis of survival among the treatment groups was performed using the Statistical Package for Social Sciences (SPSS for Window 15.0; SPSS Inc., Chicago, IL) with the Log Rank test. $P$ values $<0.05$ were considered to be statistically significant.

\section{Results}

\section{Prolonged survival of islet allografts in B6 mice with chemically induced diabetes}

After transplantation of allogeneic islets (300 IEQ) into the diabetic mice, all recipients became normoglycemic within 1 day after transplantation, and no recipients were lost because of primary nonfunctioning transplants (Figure 1A).

To examine the effect of immunosuppression on survival of the islet grafts, diabetic transplant recipient mice were assigned to 1 of 4 different groups $(n>5)$ according to their immunosuppressive treatment regimens. The grafts in the group of mice that received no immunosuppressive treatment (control) were invariably lost within about 50 days [Median graft survival time $(\mathrm{MST})=44$ days; $0 \%$ graft survival after 47 days] (Figure 1B). The group of mice that received a short treatment with Ros A alone showed a MST $=53$ days $(0 \%$ graft survival after 121 days), and the group treated with only MR1 displayed a significant prolongation of graft survival, relative to the control and Ros $A$ alone groups (MST $=82 ; 33 \%$ graft survival after 150 days). In contrast, administration of the double therapy (Ros A plus MR1) led to a remarkable prolongation of $100 \%$ graft survival ( $>160$ days), which constituted a significant difference $(P=$ $0.011)$ between the double-treated and MR1-alone therapy groups.

The graft-bearing kidneys from long-term graftbearing mice were removed 164 days after transplantation in order to confirm allograft acceptance. 
A

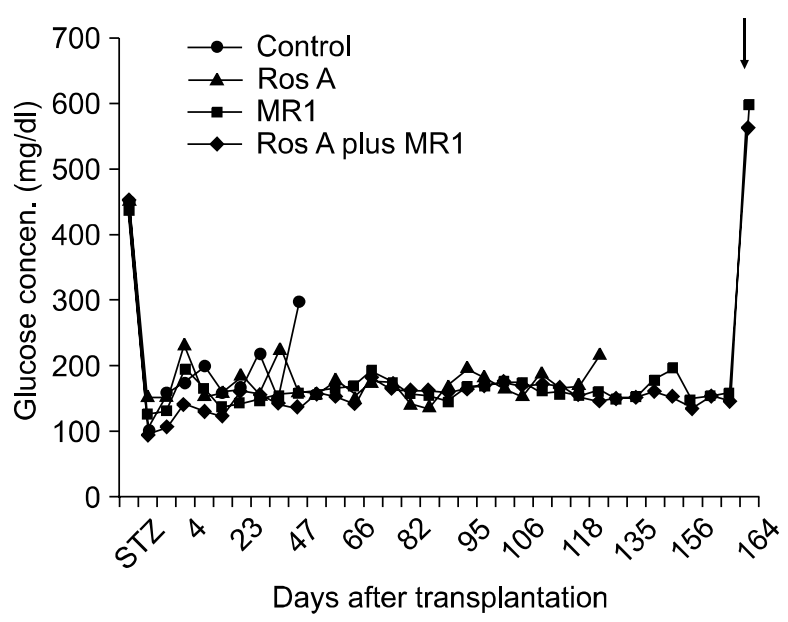

B

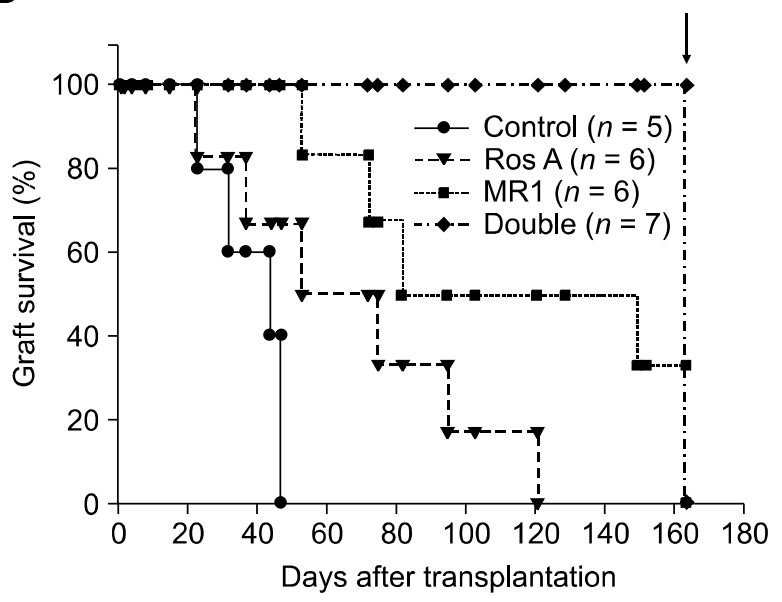

Figure 1. Effect of islet transplantation on glucose tolerance and graft survival. Shown are (A) the mean plasma glucose concentration [Glucose concen. $(\mathrm{mg} / \mathrm{dll})$ ] and (B) the percent graft survival [Graft survival (\%)] in diabetic mice that underwent allogeneic mouse islet transplantations. In order to confirm long-term graft function and acceptance, normoglycemic mice underwent unilateral nephrectomys of the graft-bearing kidneys at the time points indicated by arrows in $(A)$ and $(B)$.

After nephrectomy, the allografts were maintained in culture, upon which their survival plummeted (Figure 1B). At the same time, a recurrence of hyperglycemia was evident in the nephrectomized mice (Figure $1 \mathrm{~A}$ ), which suggests that the diabetic condition was reversed by islet transplantation and reappeared when the graft was removed.

\section{Glucose tolerance of islet allografts}

To study the effect of transplanted islets on the whole-body glucose disposal rate, IPGTTs were performed on short- and long-term functioning islet recipients at $15,85,123$, and 153 days after transplantation. As shown in Figure 2, in response to an IP injection of a high dose of glucose (2 $\mathrm{g} / \mathrm{kg}$ ), the elevated blood glucose concentrations in recipients were restored to the normal range within $2 \mathrm{~h}$. The amplitude of the blood glucose induction and the kinetics of blood glucose decline did not differ significantly among the treatment groups.

\section{Cytokine and cell surface molecule profiles}

The cytokine concentrations and distribution of $T$ cell subsets were analyzed in splenocytes that had been isolated from graft recipients 15 days after transplantation. The results of these assays showed no difference in the production of IFN- $\gamma$ and IL-4 among the various treatment groups (Figure $3 \mathrm{~A}$ and $\mathrm{B}$ ). The numbers of $\mathrm{CD} 4^{+}, \mathrm{CD} 8^{+}$, and $\mathrm{CD} 69^{+} \mathrm{T}$ cells in the splenocyte preparations from the recipients did not differ among the 4 treatment groups (Figure $4 \mathrm{~A}, \mathrm{~B}$ and $\mathrm{C}$ ). The proportion of $\mathrm{CD} 4^{+} \mathrm{T}$ cells that displayed the $\mathrm{CD} 25^{+}$phenotype was slightly decreased in transplant recipients that were treated with the MR1-alone therapy (Figure 4D).

\section{Cellular infiltrates and apoptosis in short-term allografts}

In all short-term allografts, histological analysis of the graft-bearing kidneys showed peri-islet mononuclear cell infiltration with preservation of the islet morphology. In recipients that received only Ros A, immunohistochemistry was performed on grafts that were removed 15 days after transplantation and showed a reduction in the relative proportion of $\mathrm{CD}^{+} \mathrm{T}$ cells within the infiltrate, relative to control animals. Again, insulin- and glucagon-containing cells were easily detected in the Ros A animals (Figure 5). Grafts that were treated with MR1-alone or with the double therapy showed larger islet clusters and a fewer lymphocytes and infiltrating $\mathrm{CD}^{+}{ }^{+}$cells, relative to Ros A-treated grafts. Especially in the double treatment group, insulin- and glucagon-containing cells were more easily detected than in the MR1 treatment group (Figure 5).

The TUNEL apoptosis assay was performed to detect islet cell death. In the untreated control graft recipients, which all had short-term allografts, the islet clusters showed numerous TUNEL-positive cells (Figure $6 \mathrm{~A}$ and $\mathrm{E}$ ). The grafts that were treated with the either Ros A or MR1 alone con- 
A

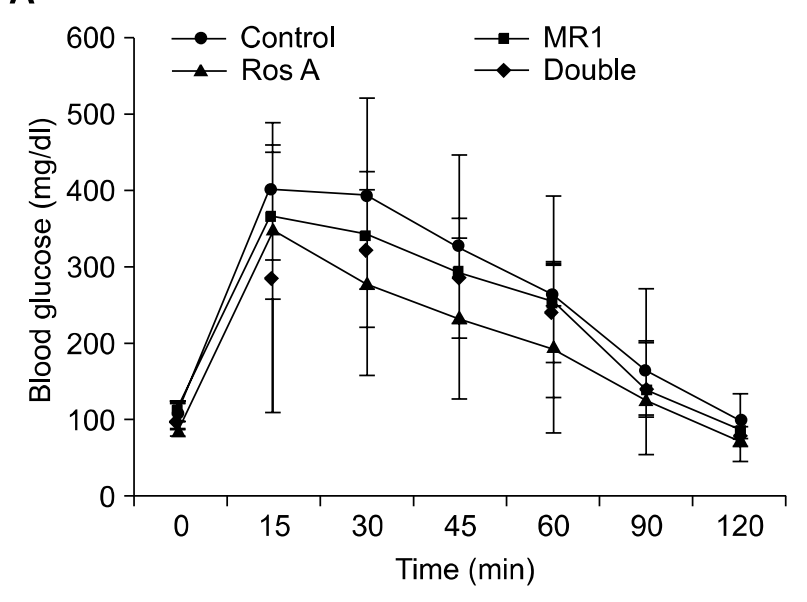

C

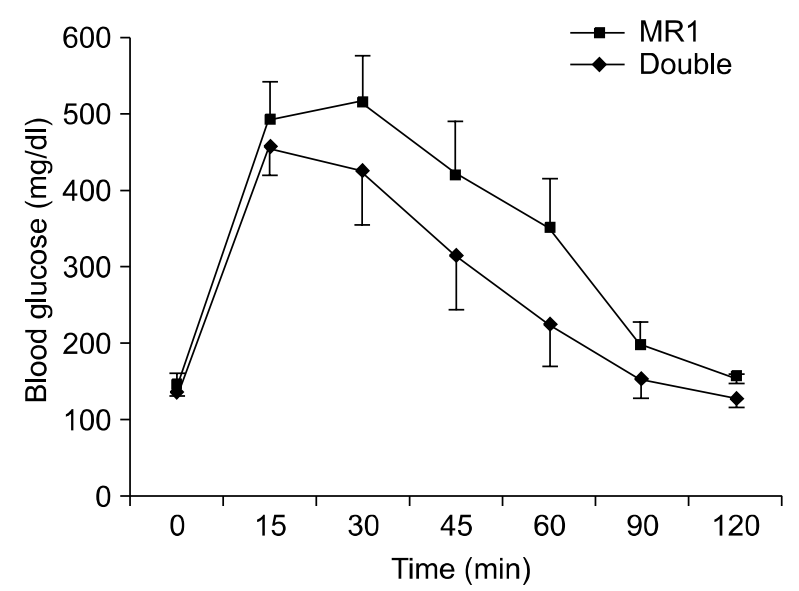

B

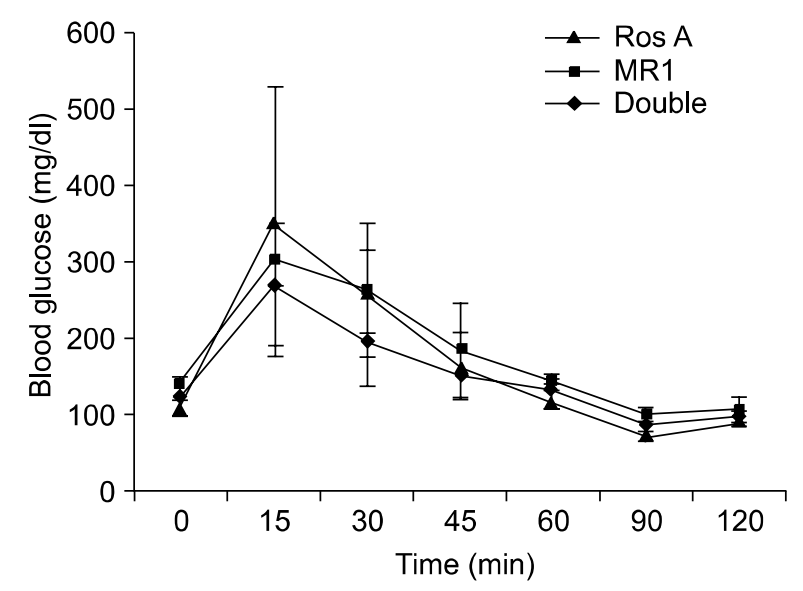

D

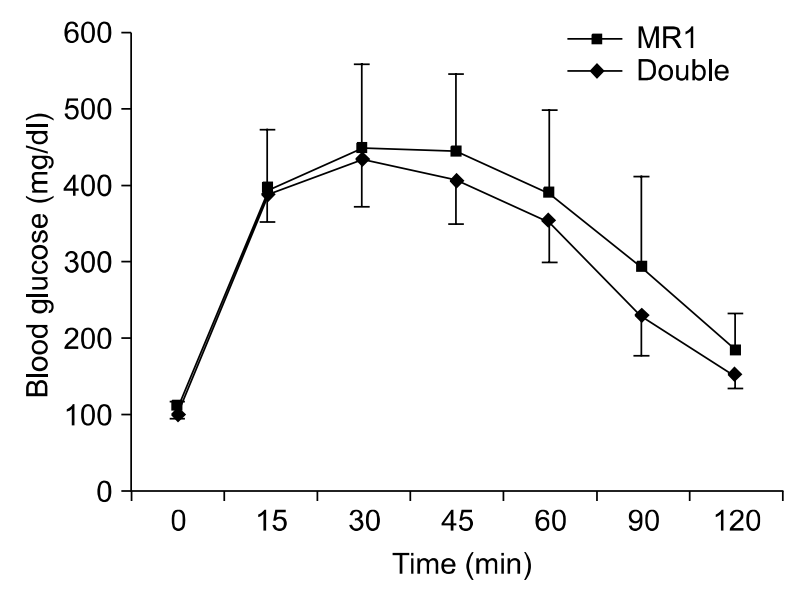

Figure 2. Intraperitoneal glucose tolerance test (IPGTT) following allogeneic islet transplantation. Islets were transplanted into C57BL/6 mice with chemically induced diabetes, and the animals were divided into four treatment groups [control, Ros A, MR1, and Ros A plus MR1 (double); see figure]. At 15 (A), $85(B), 123(C)$, and $153(D)$ days post-transplantation, mice with long-term islet grafts received an IP injection of a high dose of glucose $(2 \mathrm{~g} / \mathrm{kg})$ (time $=0$ $\mathrm{min})$, blood was collected from these animals at $0,15,30,45,60,90$, and 120 min after injection, and the blood glucose concentrations in the samples were measured. The results of the assays for all groups are expressed as the mean plasma glucose concentration [Blood glucose (mg/dl)]. $n$, number of animals in each group; time (min), time after glucose injection.

tained a few scattered TUNEL positive cells, especially outside of the area of the islet cluster, compared with control grafts (Figure 6, B and E, C and $\mathrm{E}$, respectively; $P<0.05)$. In contrast, the double-treated grafts displayed very few or no TUNEL positive cells (Figure 6D and $E$ ), relative to the grafts that were treated with $\operatorname{RosA}(P<0.005)$ or MR1 therapy $(P<0.05)$.

\section{Cellular infiltrates in long-term allografts}

Among the treated groups, only allografts that received the MR1-alone or the double treatments maintained normoglycemic conditions and survived more than 164 days after transplantion. We removed the graft-bearing kidneys from all animals in the treatment groups with long-term ( $>164$ days) functioning grafts and subjected the kidneys to immunohistochemical staining with anti-CD3, antiinsulin, and anti-glucagon antibodies (Figure 7). Islets from the double-treated animals contained relatively larger islet clusters, and more cells that stained positively for insulin and glucagons, relative to islet from the MR1-alone treatment group. 
A

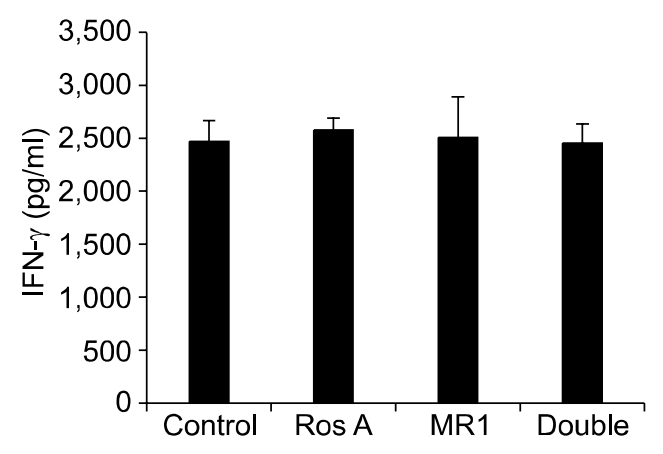

B

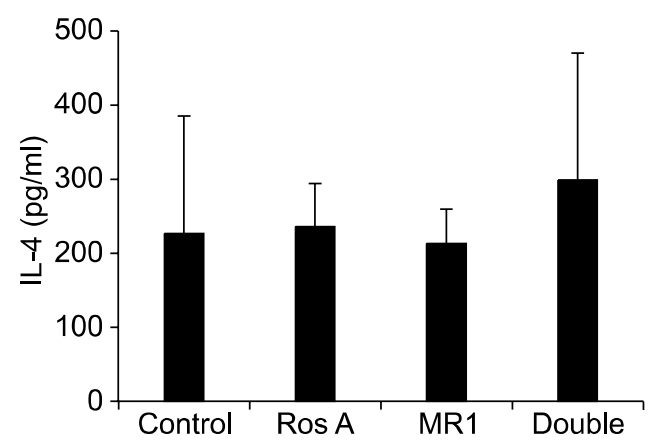

Figure 3. Cytokine production in islet allografts. The quantitative expression of IFN- $\gamma(\mathrm{A})$ and IL-4 (B) in splenocytes from recipient C57BL/6 mice treated with the indicated immunosuppressive regimens was assessed by ELISA. Results are expressed as mean \pm SD for three individual experiments.

\section{Discussion}

In the present study, we evaluated the synergistic effect of Ros A in combination with MR1 in a murine allogeneic islet transplantation model. Our results indicate that this combination ("double") therapy functions to synergistically prolonged graft survival, relative to the MR1-alone treatment group $(P=0.011)$.

When considered together, the data we obtained with the various treatment groups provide clues as to the immunosuppressive mechanisms at work in the treatment regimens tested in this study. According to previous report, Ros A inhibits TCRinduced $T$ cell activation and proliferation (Won et al., 2003), perhaps by one or both of the following mechanisms: (1) Ros A might suppress $T$ cell activation in response to the transplanted graft in vivo and/or (2) Ros A, a TCR-signaling inhibitor, may synergize with other immuosupressants that inhibit signaling cascades distinct from TCR signaling. Finally, Won et al. (2003) demonstrated that a combined therapy of two differently functioning immunosuppressants synergistically inhibits $\mathrm{T}$ cell

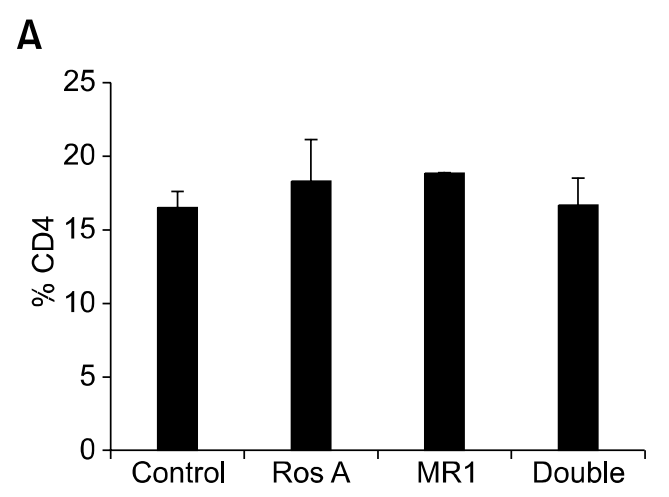

B

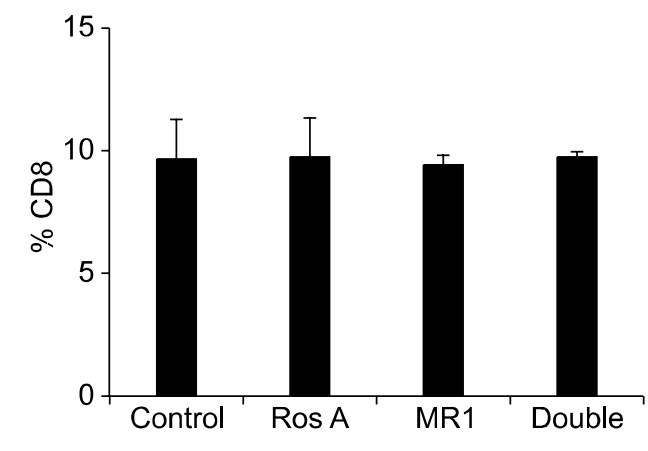

C

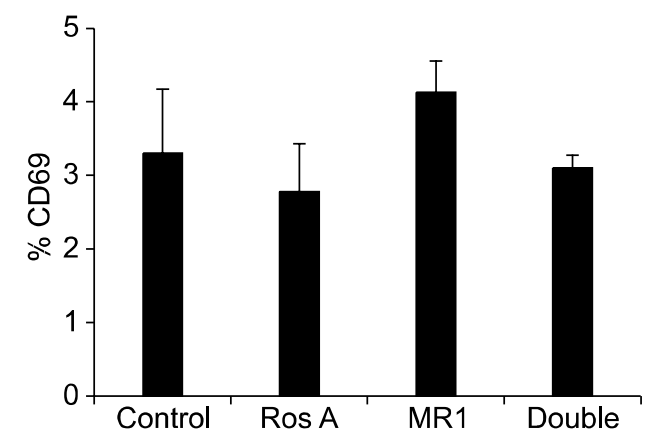

D

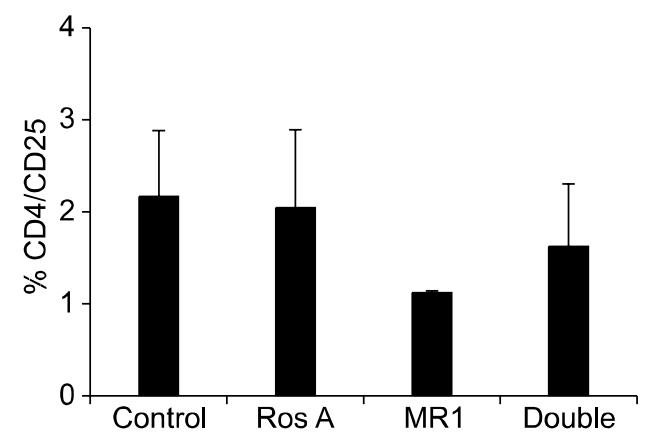

Figure 4. Flow cytometry used to assess the T cell phenotypes in the islet allografts. Shown are the proportions (\%) of splenocyte-derived $\mathrm{CD} 4^{+}$ (A), $\mathrm{CD}^{+}(\mathrm{B}), \mathrm{CD}^{+} 9^{+}$(C) and $\mathrm{CD}^{+} / \mathrm{CD}^{+} 5^{+}$(D) T cells in recipient C57BL/6 mice treated with the indicated immunosuppressive regimens. Results are expressed as mean $\pm S D$ of at least three separate experiments. 

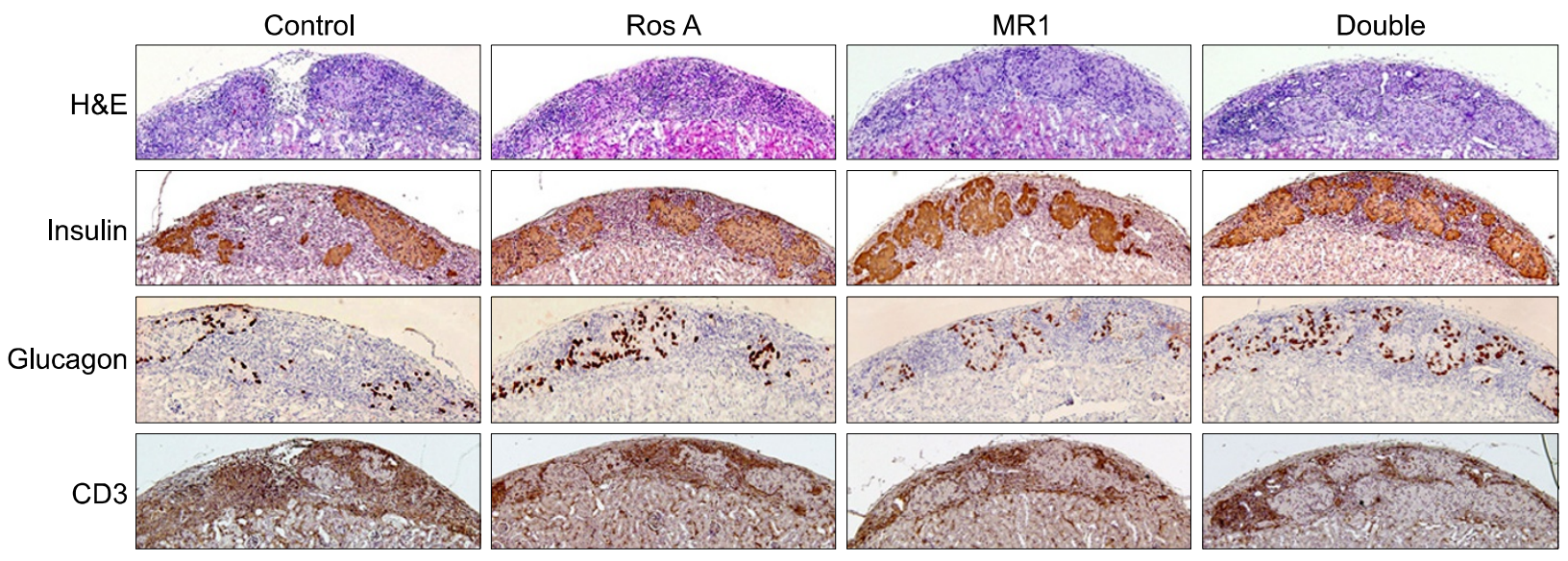

Figure 5. Comparison of islet allograft histology in recipients from each of the 4 treatment groups (displayed in vertical columns). Functioning islets allografts in the renal subcapsular space of diabetic C57BL/6 mice were removed on day 15 after transplantation. Line 1, hematoxylin/eosin staining (H\&E). Other lines show immunoperoxidase staining for antibodies to insulin (line 2), glucagons (line 3) and CD3 (line 4), (magnification $\times 100$ ). Histological sections for each marker are representative of three animals from each treatment group.
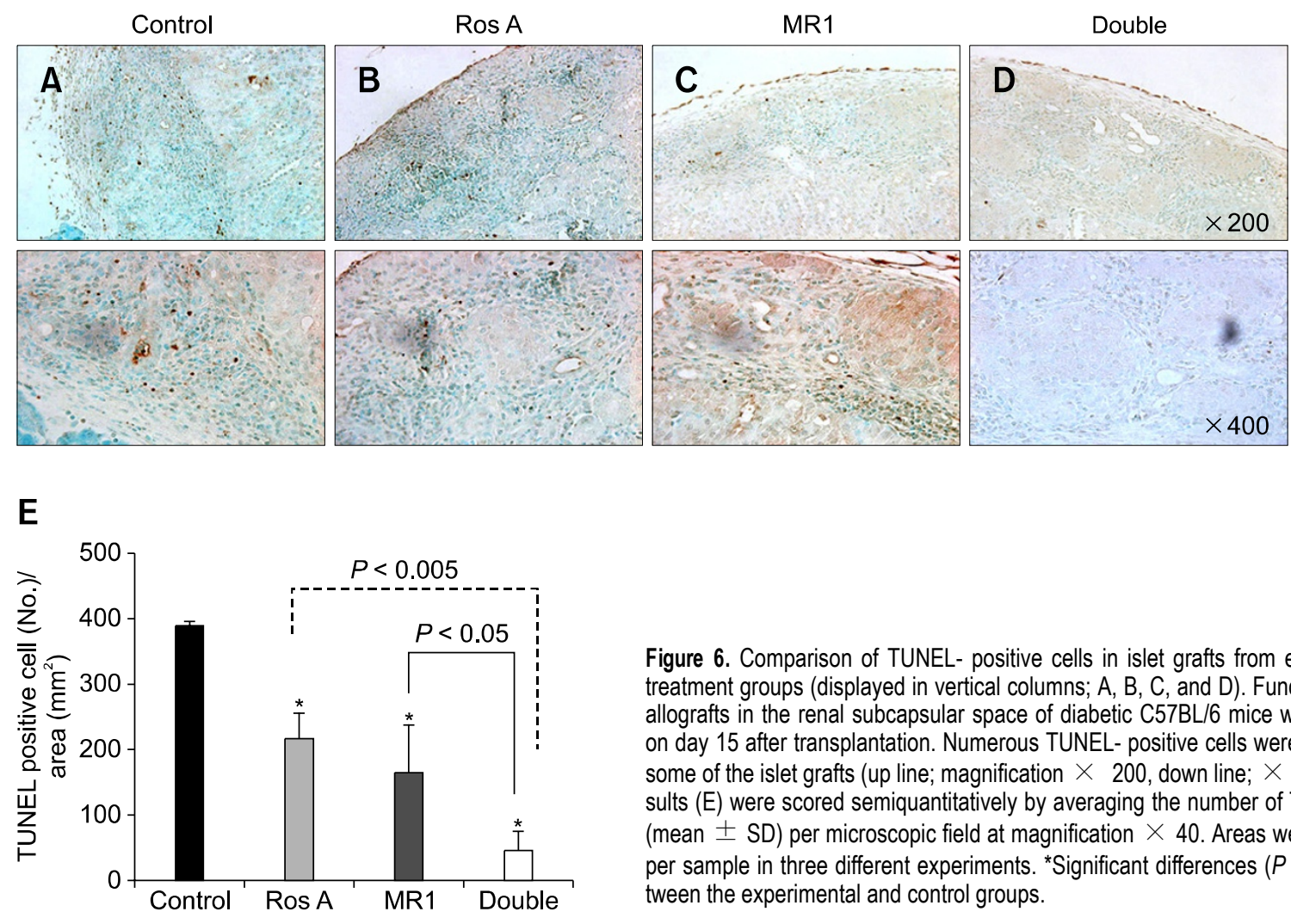

Figure 6. Comparison of TUNEL- positive cells in islet grafts from each of the 4 treatment groups (displayed in vertical columns; A, B, C, and D). Functioning islets allografts in the renal subcapsular space of diabetic C57BL/6 mice were removed on day 15 after transplantation. Numerous TUNEL- positive cells were observed in some of the islet grafts (up line; magnification $\times 200$, down line; $\times 400$ ). The results $(E)$ were scored semiquantitatively by averaging the number of TUNEL ${ }^{+}$cells (mean $\pm \mathrm{SD}$ ) per microscopic field at magnification $\times 40$. Areas were evaluated per sample in three different experiments. ${ }^{*}$ Significant differences $(P<0.05)$ between the experimental and control groups.

proliferation and, consequently, prolongs mouse skin graft survival; Won et al. (2003) used Ros A, which inhibits TCR-induced IL-2 expression, and Rapa, which inhibits IL-2 receptor-mediated T-cell proliferation (Yun et al., 2003). Another known effect of Ros $A$ is that it participates in the promotion of $\mathrm{T}$ cell apoptosis. A recent study with rheumatoid arthritis (RA) patients indicated that Ros A induces apoptosis of activated $T$ cell subsets-including $\mathrm{CD}^{+} / \mathrm{CD} 25^{+}, \mathrm{CD} 4^{+} / \mathrm{CD} 25^{+}$, and $\mathrm{CD}^{+} / \mathrm{CD} 4 \mathrm{RO}^{+} \mathrm{T}$ cells-via a mitochondrial pathway (Hur et al., 2007). 


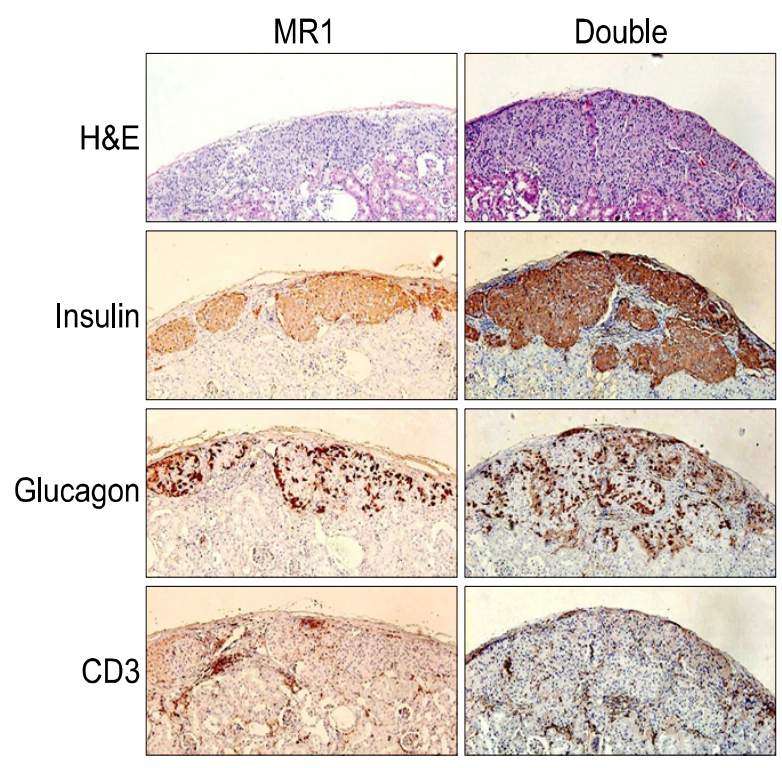

Figure 7. Comparison of islet allograft histology in recipients from 2 of the treatment groups (displayed in vertical columns). Functioning islet allografts in the renal subcapsular space of diabetic C57BL/6 mice were removed on day 164 after transplantation. Line 1, hematoxylin/eosin staining (H\&E). Other lines show immunoperoxidase staining for antibodies to insulin (line 2), glucagons (line 3), and CD3 (line 4) (magnification $\times 100$ ). Histological sections for each marker are representative of two to seven live animals from each treatment group.

To evaluate the synergistic effect of Ros A plus MR1 (the double therapy) in a murin allogeneic skin graft model, skin grafts from BALB/c mice were transplanted into $\mathrm{C} 57 \mathrm{BL} / 6$ mice that had been treated with the double therapy. The results show that only a $33 \%$ survival was achieved in the recipients (MST $=24$ days, data not shown). Survival of these skin grafts was slightly longer than that of MR1-treated animals, but the differences were not significant. Therefore, we suggest that the beneficial effect of the double therapy on graft survival was greater in the islet transplantation model described herein than in our much more stringent skin transplantation model. In our allogeneic islet transplantation model, the proportions of activated and effector T cells, including $\mathrm{CD}^{+} 9^{+}$, $\mathrm{CD}^{+} / \mathrm{CD} 25^{+}$, and $\mathrm{CD}^{+} / \mathrm{CD} 45 \mathrm{RB}^{+}$, were not significantly different in the MR1-only and the double therapy animals. We also found that cytokine production by Thelper 1 cells (Th1s) and Th2s in the double-treated animals was similar to that of the MR1-only group. Thus, we suggest that the effect of Ros A as an immunosuppressant may be specific to the experimental model used in a given study. Our results also indicate that the prolonged survival observed for the double treatment group in the allogeneic islet transplantation model was associated only weakly with the immunosuppres- sive effect of Ros $A$.

As shown in our study, the treatment with either Ros A, MR1, or both reduces early cellular infiltration in the allograft when compared with the control group, but no difference in this parameter was observed between the MR1-only and double therapy groups. In contrast, insulin- and glucagonscontaining cells in the grafts treated with the double therapy were more easily detected when compared with grafts that had received the MR1only therapy. Again, the number of TUNEL-positive cells was reduced markedly in the double-treated graft. Together, these observations imply that Ros A may have beneficial effects on physiology and, thus, graft survival that are separate from its immunosuppressive action, at least when Ros A is administered concomitantly with MR1 in an allogeneic islet transplantation model.

In fact, it is known that Ros A inhibits inflammation in animal models of liver injury, such as typical hepatic necrosis and apoptosis followed by fulminate hepatitis. (Osakabe et al., 2002). The liver protection of Ros $A$ is due to the scavenging or reducing activities-superoxide or peroxynitirite. Free radicals can act as (i) mediators of inflammation, (ii) activators of iNOS during chronic infection, or (iii) inducers of excessive NO production during inflammation (Lambeth, 2004). Intracellular NO can react with superoxide anions, resulting in the formation of the potent oxidizing and nitrating molecule peroxynitrite. These reactive nitrogen species can have toxic effect on mitochondria and cause damage to macromolecules, such as DNA, proteins, and lipids. A recent study has shown that Ros A can also act as an effective protector against peroxynitrite-mediated damage and as a potent inhibitor of superoxide and NO synthesis; inhibition of ROS and reactive nitrogen species formation is achieved partly by the ability of Ros A to inhibit serine phosphorylation of $\mathrm{I}_{\kappa}-\mathrm{B} \alpha$, an inhibitor of the transcription factor NF-kB (Qiao et al., 2005). Therefore, precise regulation of superoxide and NO production appears to be critical for the survival of islet grafts in our model.

Furthermore, because Ros A inhibits the complement inflammatory process and has anti-thrombotic and anti-platelet effects (Zou et al., 1993; Sahu et al., 1999; Zupko et al., 2001), we suspect that Ros A may also have therapeutic potential for protecting against the immediate blood-mediated inflammatory reaction (IBMIR) often observed in clinical islet transplantation.

In conclusion, our islet recipients treated with the double therapy showed significantly delayed islet allograft rejection. However, prolonged islet graft survival was not associated with changes in the T 
cell population or the level of cytokine expression. Because a marked decrease in the number of apoptotic cells and larger islet clusters were observed in double-treated grafts, relative to those of the other treatment groups, we hypothesize that, in our allogeneic islet transplantation model, Ros $A$ may inhibit the production of ROS and reactive nitrogen species, or in some other way protect tissues against the damage caused by these metabolites. Finally, we suggest that Ros A treatment combined with MR1 has a synergistic effect on graft survival in murine islet allotransplantation.

\section{Acknowledgment}

This research was supported by grants from the IN-SUNG Foundation for medical research (C-A5-821-1).

\section{References}

al-Sereiti MR, Abu-Amer KM, Sen P. Pharmacology of rosemary (rosmarinus officinalis linn.) and its therapeutic potentials. Indian J Exp Biol 1999;37:124-30

Eng CP, Gullo-Brown J, Chang JY, Sehgal SN. Inhibition of skin graft rejection in mice by rapamycin: a novel immunosuppressive macrolide. Transplant Proc 1991;23:868-9

Gotoh M, Maki T, Kiyoizumi T, Satomi S, Monaco AP. An improved method for isolation of mouse pancreatic islets. Transplantation 1985;40:437-8

Hojo M, Morimoto T, Maluccio M, Asano T, Morimoto K, Lagman M, Shimbo T, Suthanthiran M. Cyclosporine induces cancer progression by a cell-autonomous mechanism. Nature 1999;397:530-4

Hur YG, Yun Y, Won J. Rosmarinic acid induces p56lckdependent apoptosis in jurkat and peripheral $t$ cells via mitochondrial pathway independent from fas/fas ligand interaction. J Immunol 2004;172:79-87

Hur YG, Suh CH, Kim S, Won J. Rosmarinic acid induces apoptosis of activated $t$ cells from rheumatoid arthritis patients via mitochondrial pathway. J Clin Immunol 2007; 27:36-45

Jung DY, Lee HJ, Lee EN, Lee J, Kim EY, Park HJ, Chang CY, Lee SK, Joh JW, Kwon GY, Kim SJ. Beneficial effects of simultaneous treatment with 15-deoxyspergualin and monoclonal antibodies to CD45RB and CD154 on murine islet transplantation recipients. Transplantation 2006;82: 188-95

Kaufman DB, Gores PF, Field MJ, Farney AC, Gruber SA, Stephanian E, Sutherland DE. Effect of 15-deoxyspergualin on immediate function and long-term survival of transplanted islets in murine recipients of a marginal islet mass. Diabetes 1994;43:778-83

Kelm MA, Nair MG, Strasburg GM, DeWitt DL. Antioxidant and cyclooxygenase inhibitory phenolic compounds from ocimum sanctum linn. Phytomedicine 2000;7:7-13
Kenyon NS, Chatzipetrou M, Masetti M, Ranuncoli A, Oliveira M, Wagner JL, Kirk AD, Harlan DM, Burkly LC, Ricordi C. Long-term survival and function of intrahepatic islet allografts in rhesus monkeys treated with humanized anti-cd154. Proc Natl Acad Sci USA 1999;96:8132-7

Lambeth JD. Nox enzymes and the biology of reactive oxygen. Nat Rev Immunol 2004;4:181-9

Lenschow DJ, Zeng Y, Thistlethwaite JR, Montag A, Brady W, Gibson MG, Linsley PS, Bluestone JA. Long-term survival of xenogeneic pancreatic islet grafts induced by ctla4lg. Science 1992;257:789-92

Molano RD, Berney T, Li H, Cattan P, Pileggi A, Vizzardelli C, Kenyon NS, Ricordi C, Burkly LC, Inverardi L. Prolonged islet graft survival in nod mice by blockade of the cd40-cd154 pathway of t-cell costimulation. Diabetes 2001;50:270-6

Osakabe N, Yasuda A, Natsume M, Sanbongi C, Kato Y, Osawa T, Yoshikawa T. Rosmarinic acid, a major polyphenolic component of perilla frutescens, reduces lipopolysaccharide (Ips)-induced liver injury in d-galactosamine (d-galn)-sensitized mice. Free Radic Biol Med 2002;33:798806

Parker DC, Greiner DL, Phillips NE, Appel MC, Steele AW, Durie FH, Noelle RJ, Mordes JP, Rossini AA. Survival of mouse pancreatic islet allografts in recipients treated with allogeneic small lymphocytes and antibody to cd40 ligand. Proc Natl Acad Sci USA 1995;92:9560-4

Porte D Jr. Banting lecture 1990. Beta-cells in type ii diabetes mellitus. Diabetes 1991;40:166-80

Qiao S, Li W, Tsubouchi R, Haneda M, Murakami K, Takeuchi F, Nisimoto $Y$, Yoshino M. Rosmarinic acid inhibits the formation of reactive oxygen and nitrogen species in raw264.7 macrophages. Free Radic Res 2005;39:995-1003

Ricordi C. Islet transplantation: A brave new world. Diabetes 2003;52:1595-603

Sahu A, Rawal N, Pangburn MK. Inhibition of complement by covalent attachment of rosmarinic acid to activated c3b. Biochem Pharmacol 1999;57:1439-46

Tisch R, McDevitt H. Insulin-dependent diabetes mellitus. Cell 1996;85:291-7

van Kessel KP, Kalter ES, Verhoef J. Rosmarinic acid inhibits external oxidative effects of human polymorphonuclear granulocytes. Agents Actions 1986;17:375-6

Won J, Hur YG, Hur EM, Park SH, Kang MA, Choi Y, Park C, Lee $\mathrm{KH}$, Yun Y. Rosmarinic acid inhibits tcr-induced $t$ cell activation and proliferation in an Ick-dependent manner. Eur J Immunol 2003;33:870-9

Yun SY, Hur YG, Kang MA, Lee J, Ahn C, Won J. Synergistic immunosuppressive effects of rosmarinic acid and rapamycin in vitro and in vivo. Transplantation 2003;75:1758-60

Zheng XX, Markees TG, Hancock WW, Li Y, Greiner DL, Li XC, Mordes JP, Sayegh MH, Rossini AA, Strom TB. CTLA4 signals are required to optimally induce allograft tolerance with combined donor-specific transfusion and anti-cd154 monoclonal antibody treatment. J Immunol 1999;162:498390 
Zou ZW, Xu LN, Tian JY. antithrombotic and antiplatelet effects of rosmarinic acid, a water-soluble component isolated from radix salviae miltiorrhizae (danshen). Yao Xue Xue Bao 1993;28:241-5

Zupko I, Hohmann J, Redei D, Falkay G, Janicsak G, Mathe
I. Antioxidant activity of leaves of salvia species in enzyme-dependent and enzyme-independent systems of lipid peroxidation and their phenolic constituents. Planta Med 2001;67:366-8 